\title{
PERSPECTIVE
}

\section{Astigmatism and the analysis of its surgical correction}

\author{
Nigel Morlet, Darwin Minassian, John Dart
}

Modern cataract and refractive surgery aims not only to improve vision but to provide a good unaided visual acuity. Correcting astigmatic errors and control of surgically induced astigmatism are now an integral part of such operative procedures. Technological innovations and surgical developments in recent times have provided new methods for correction of astigmatism. However, evaluating the outcome of surgery for astigmatism presents particular difficulties, especially with the statistical comparison of different treatment groups.

In this review we will discuss the nature of astigmatism and its various refractive effects and how this relates to cataract and refractive surgical outcomes. The use and limitations of vectors and other methods for the analysis of change in astigmatism after surgery will be discussed along with appropriate statistical methods and suggestions for data presentation.

\section{Ocular astigmatism}

Astigmatism occurs when toricity of any of the refractive surfaces of the optical system produces two principal foci delimiting an area of intermediate focus called the conoid of Sturm. Thomas Young in 1801 was the first to describe ocular astigmatism, discovering that his own astigmatism was predominantly lenticular. ${ }^{1}$ However, it was some years later before Airy (1827) corrected astigmatism with a cylindrical lens. ${ }^{2}$ Corneal astigmatism was characterised by Knapp and also Donders in 1862 after the invention of the ophthalmometer by Helmholtz. ${ }^{34}$ In the same year Donders $^{5}$ also described the astigmatism due to cataract surgery and soon after Snellen (1869) suggested that placing the incision on the steep axis would reduce the corneal astigmatism. ${ }^{6}$ Surgery to specifically treat astigmatism was suggested by Bates ${ }^{7}$ who described corneal wedge resection in 1894, but it was the work of Lans ${ }^{8}$ that provided most of the early theoretical basis for refractive corneal surgery. Little further work was published until that of Sato in the 1940s and 1950s. ${ }^{9}{ }^{10}$ However, with the development of microsurgical techniques in the 1970s, Troutman once again popularised wedge resection and keratotomy for the reduction of astigmatism. ${ }^{112}$

Why correct astigmatism?

Astigmatism induces distortion of the image. ${ }^{13-15}$ When the effects of blurring of the image are excluded, the retinal image in an uncorrected astigmatic eye is distorted because of a differential magnification in the two principal meridians. Expressed as a percentage of the differences in these principal meridians (see equation 1 in the appendix), the image is distorted by about $0.3 \%$ per dioptre of astigmatism. ${ }^{14-16}$ In the corrected astigmatic eye, distortion of the sharp retinal image arises from the unequal spectacle magnification in the two principal meridians, which represents about $1.6 \%$ distortion per dioptre cylinder in the correction at the spectacle plane. This unequal magnification is manifest by altered shapes and by tilting of vertical lines (the declination error) that occurs maximally when the correcting cylinder is oblique (that is, $45^{\circ}$ or $\left.135^{\circ}\right) .{ }^{13-21}$ Although oblique astigmatism only produces $0.4^{\circ}$ of tilt per dioptre monocularly, it will produce major alterations in binocular perception. ${ }^{2}$

Despite the distortion induced by astigmatism, some astigmatism may be of benefit. ${ }^{14}{ }^{1522-27}$ Various types of astigmatism have different effects on visual perception. For this reason the concepts of astigmatism "with the rule" (WTR) and "against the rule" (ATR) are clinically relevant. Astigmatism WTR is produced when the corneal curvature is steepest in the vertical meridian; conversely astigmatism ATR is produced when the steepest corneal meridian is horizontal.

Figure 1 shows how the power of the weaker principal meridian produces a vertical line focus (Fbeta) in astigmatism WTR. In printed matter the vertical strokes of letters are more important for recognition-for example, b, d, h, $\mathrm{t}, \mathrm{p}, \mathrm{y}$, also there is less space between letters on a line than between lines. In these circumstances it is most useful to
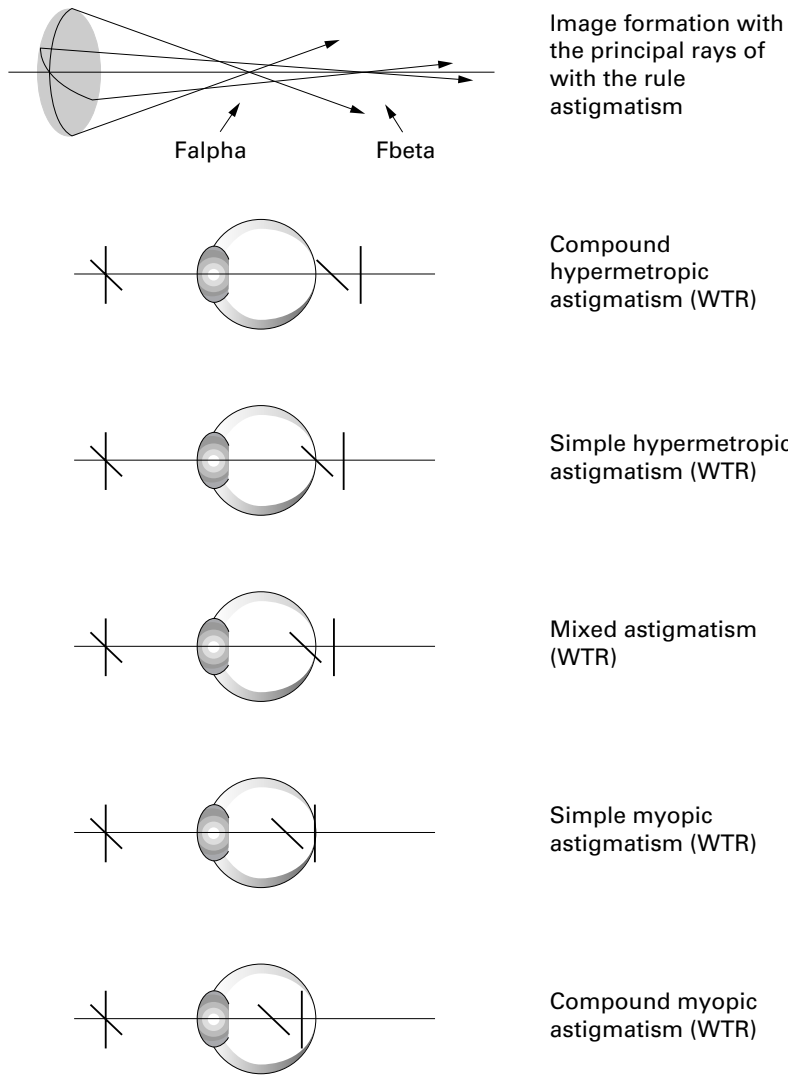

Figure 1 Diagram showing the principal rays in the formation of an astigmatic image. Falpha is the anterior focal point, convergent light rays from the steeper meridian produce a horizontal line focus. Fbeta is the posterior focal point from the flatter meridian producing a vertical line focus. In this example, when Fbeta is coincident with the retina, simple myopic astigmatism with the rule is produced. 
Table 1 The approximate relation of unaided visual acuity and required correction (in dioptres) from 6000 refractions in young adults (males and females $<30$ years). The size of the plus cylinder for a given uncorrected astigmatic error was approximately 1.4 times greater than the spherical equivalent for an oblique axis, increasing to 1.6 times for a vertical axis (with the rule astigmatism) and 2.0 times for horizontal axis (against the rule astigmatism). The latter reducing to $1.8 \times$ when the VA was worse than 20/150. This demonstrates that against the rule astigmatism has a worse unaided VA and requires a larger cylinder correction than an equivalent with the rule astigmatism (that is, for any given spherical equivalent) ${ }^{29}$

\begin{tabular}{|c|c|c|c|c|c|c|c|c|c|}
\hline Visual acuity & $20 / 30$ & $20 / 40$ & $20 / 50$ & $20 / 70$ & $20 / 100$ & $20 / 150$ & $20 / 200$ & $20 / 250$ & $20 / 300$ \\
\hline Astigmatism axis horizontal & 1.00 & 1.50 & 2.00 & 2.50 & 3.00 & 4.00 & 4.50 & 5.50 & 6.25 \\
\hline Astigmatism axis vertical & 0.75 & 1.25 & 1.50 & 2.00 & 2.50 & 3.25 & 4.00 & 4.25 & 5.50 \\
\hline Astigmatism axis oblique & 0.75 & 1.00 & 1.50 & 1.75 & 2.25 & 2.75 & 3.50 & 4.25 & 5.00 \\
\hline Spherical myopia or absolute hypermetropia & 0.50 & 0.75 & 1.00 & 1.25 & 1.50 & 2.00 & 2.50 & 3.00 & 3.50 \\
\hline
\end{tabular}

have a better focus in the vertical meridian, as is produced by myopic astigmatism WTR resulting in better Snellen visual acuity than with ATR astigmatism. ${ }^{14}{ }^{15}$ 28-30 Table 1 shows the effect of the orientation of the axis of astigmatism on Snellen visual acuity as described by Eggers. ${ }^{29}$ In addition, a number of psychophysiological responses are more sensitive to vertically oriented stimuli-for example, the stereoscopic threshold, the cyclodisparity range for fusion, and the monocular determination of depth using parallax errors. ${ }^{16} 2021$

Another little recognised advantage of astigmatism WTR is that less cylinder is required in the spectacle correction than for astigmatism ATR of the same magnitude. $^{141531}$ This is known as Javal's rule (equation 2 in appendix $)^{32}$ and may partly explain the problem in only using keratometric data for the planning of refractive surgery described by some authors. ${ }^{33} 34$

The reason for this relation is uncertain and could result from either lenticular astigmatism or a disproportionally shorter posterior corneal radius in the vertical meridian. ${ }^{31}$ Whether Javal's rule still holds after cataract extraction and intraocular lens implantation has not been determined; however, there is evidence that the spectacle cylinder correction is different from the keratometric astigmatism. ${ }^{21}$

Also, it is often not recognised that the spectacle cylinder will be less than the ocular astigmatism when the spherical equivalent $\left(\mathrm{S}_{\mathrm{EQ}}\right)$ is positive, and greater than the ocular astigmatism when $S_{\mathrm{EQ}}$ is negative ${ }^{14313536}$ (equation 3). So in general, myopic ATR astigmatism will result in a proportionally larger spectacle correction, which of course will produce more distortion.

However, a certain degree of myopic astigmatism may be useful. Although never producing a crisp focus, this refraction may produce a situation of pseudoaccommodation in the pseudophakic patient. ${ }^{21-25}$ This phenomenon was suggested originally in the 1960 s by Peters, ${ }^{22}$ and by Huber. ${ }^{23}$ Later Sawusch and Guyton produced an elegant optical model indicating the optimal cylindrical component $(\mathrm{C})$ for a given spherical equivalent $\left(\mathrm{S}_{\mathrm{EQ}}\right)^{26}$ (Fig 2, equation 4 ).

Their model suggested that the least amount of summated blur throughout the range of object distances (0.5-6 metres) was $-1.00 \mathrm{DS} /+0.75 \mathrm{DC}$, and was closely followed by $-0.75 \mathrm{DS} /+0.50 \mathrm{DC}$.

Arguing that ATR astigmatism provides a superior uncorrected near visual acuity, Trindale et al discussed the astigmatic paradox. ${ }^{27}$ This is where the divergent rays from a near point are brought to focus more posteriorly by the fixed optics of the pseudophakic eye. So for myopic ATR astigmatism the vertical meridian will be placed closer to the retina for near objects, providing better visual acuity.

Apart from the bias of the psychophysical aspects of the visual perception towards vertically orientated objects, the physical optics of the eye also suggest that a small amount of astigmatism WTR is beneficial. This means that a relative value can be assigned to the various types of ocular astigmatism.

\section{Astigmatism produced by surgery}

Since Donders's first description, it was well recognised that the wound produced by cataract surgery produced astigmatism. ${ }^{5}$ Treutler described the outcome following superior section for cataract extraction for 49 patients in $1900 .{ }^{37} \mathrm{He}$ found that the vertical curvature flattened by a mean of $0.7 \mathrm{~mm}$ (3.75D, up to $1.5 \mathrm{~mm}$ or $6.5 \mathrm{D})$ for $88 \%$ of patients, for $2 \%$ there was no change, and for $10 \%$ there was an increase in curvature. With the advent of intraocular lens implantation and sutured cataract sections, induced astigmatism became more of a concern..$^{35}$ Typically the tight sutures compressing the wound in the vertical meridian would produce an initial astigmatism WTR. Over a period of 3 months the astigmatism would change to ATR as the sutures loosened and the wound sagged with healing. ${ }^{38-42}$ The introduction of phacoemulsification of the lens nucleus and foldable intraocular lenses resulted in smaller wound producing less astigmatism. ${ }^{43-46}$ Placement of the wound on the horizontal corneal meridian has become more common and results in less change in the astigmatism as the wound heals. ${ }^{47-49}$ Although the use of different suture materials, suturing techniques, and other suture manipulations may influence the early postoperative outcome, the ultimate astigmatic result is predominately influenced by wound size and placement. ${ }^{40} 50-55$

During the evolution of change in astigmatism following cataract surgery, the patient's actual spherical equivalent will remain constant. Cravy described this effect as being not unlike a "hula hoop" where compression in one axis results in an equal expansion in the other axis. ${ }^{56} \mathrm{He}$ was in fact describing Gauss's law of elastic domes-“for every change in curvature in one meridian there is an equal and opposite change $90^{\circ}$ away." This phenomenon of corneal behaviour is known as the coupling effect. ${ }^{8758}$ Thornton restates Gauss's law as "the law of modified living elastic domesthe change in the primary meridian is proportional to the change in the primary meridian reduced by the increase in circumference." ${ }^{.57}$ Therefore the corneal curvature changes

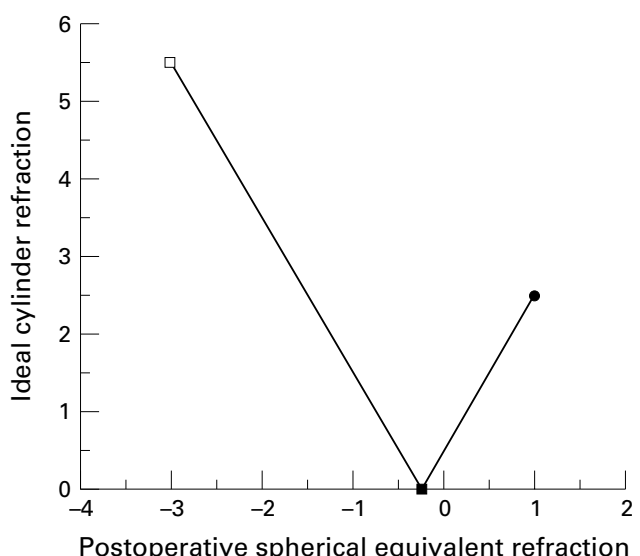

Figure 2 The ideal cylinder $(C)$ for a given spherical equivalent $\left(S_{E O}\right)$ : $C=-2 S_{E O}-0.50$ (ie, $C=-$ sphere -0.25 ), where $S_{E O}$ is $-0.25 \mathrm{D}$ or less (ie, a myopic correction) and $C$ is a plus cylinder, and $C=2 S_{E O}+0.50$, where $S_{E Q}$ is greater than $-0.25 \mathrm{D}$ (ie, a hypermetropic correction). ${ }^{26}$ 

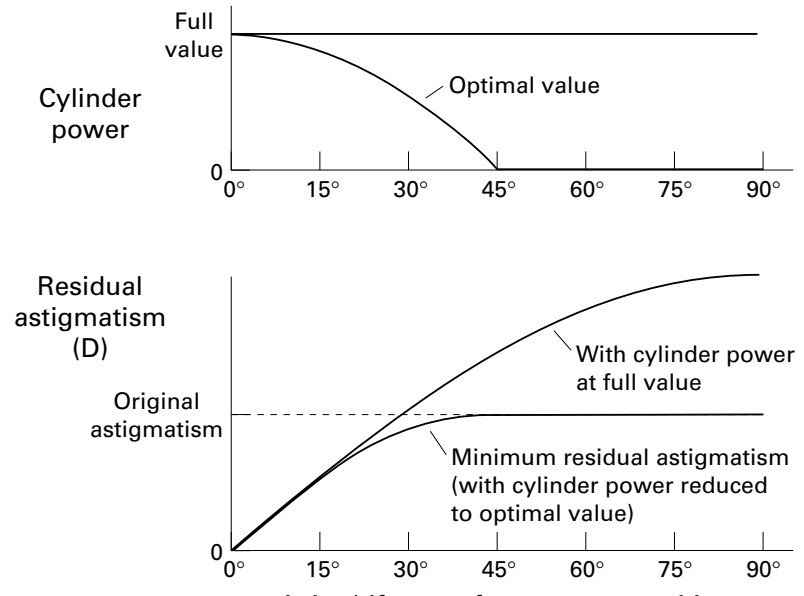

Axis shift away from correct position

Figure 3 Residual astigmatism produced when a cylinder axis is shifted away from its correct position: (Csin $\phi) D S /-2 C \sin \phi) D C$, axis $(\theta+45+$ $\phi / 2$ ), where $C$ cylinder is set at $\phi$ angle from the true axis $\theta$. Graphs illustrate how reducing the cylinder power to an "optimal value" can minimise the residual astigmatism. The optimal cylinder power in these circumstances is: $C \cos 2 \phi$, where $C$ is the original full dioptric power of the correcting cylinder, and $\phi$ is the angle the cylinder is rotated away from the correct position. So if the "optimal value" for the correct cylinder power is used the residual astigmatism is equal to $C \sin 2 \phi$, where $C$ is the original full dioptric power of the correcting cylinder and $\phi$ is the angle the cylinder is rotated away from the correct position. ${ }^{16}$

are not as if a single spherocylinder was placed at a certain axis, but as if a plus cylinder was placed in the steeper meridian and a minus cylinder of equivalent magnitude was placed in the flatter meridian (that is, a cross cylinder effect). The concept of a cross cylinder effect is an important consideration in the method of analysis of astigmatic changes.

Coupling also occurs with tangentially oriented corneal incisions and is predictable enough to form the basis for astigmatic keratotomy. ${ }^{57-60}$ Placing an incision perpendicular to the steepest corneal meridian in the mid-periphery of the cornea will flatten the curvature in that meridian as a result of wound gape. It will also result in the steepening of the flatter corneal meridian because the boundary of the cornea is fixed by the limbus. In general, the plus cylinder notation is used because the incisions are placed on the cornea straddling the axis of the plus cylinder. ${ }^{58}$

Laser photorefractive keratectomy also has the ability to correct the corneal astigmatism at the same time as correct myopia. ${ }^{61}{ }^{62}$ In effect the procedure cuts a minus cylinder from the corneal surface, so minus cylinder notation is usually used. For the correction of hypermetropic astigmatism a plus cylinder notation is used to minimise redundant ablation. The result produced is independent of the coupling phenomenon and is only influenced by the healing response of the patient changing the profile of the ablation over time.

Misalignment of the wound will result in a residual error of refraction in all types of refractive surgery. As a corrective cylinder is rotated away from its correct axis without a change in its magnitude, residual astigmatism is induced. The effect of cylinder misalignment is essentially the same as that of obliquely crossed cylinders. ${ }^{14-16} 3163$ For example a $-1.00 \mathrm{D}$ cylinder rotated $10^{\circ}$ off an intended axis of $180^{\circ}$ will result in an error of $+0.17 /-0.35 \times 140^{\circ}$ (see equation 5). A general rule of thumb for this circumstance is that the magnitude of the cylindrical error is $3.5 \%$ of $\mathrm{C}$ per degree of $\phi$ and lies about $45^{\circ}$ from the axis of C. ${ }^{64}$ This relation explains the need to adjust the sphere with any change in the cylinder power or axis during refraction. The fact that the components of the refraction are not independent of one another presents difficulties with the analysis of change in refraction, as is discussed later.
So as the axis of the cylindrical correction is rotated away from its correct position the power of the cylinder needs to be reduced in order to minimise the residual astigmatism (Fig 3, equations 5, 6, and 7). ${ }^{165-68}$

When evaluating the effect of the refractive surgery, the surgeon wishes to know what the patient's refractive result means in terms of surgical error. That is, was the error in the magnitude of the surgical correction (resulting in astigmatism of $-2 \mathrm{Csin} \phi$ ), and what was the error in axis alignment $(\phi)$ of the correction which, as discussed, has a direct influence on the magnitude error. Many of the methods of analysis suggested for this purpose follow.

\section{Vector analysis of surgery of astigmatism}

Much has been written about the vector analysis of astigmatism. $^{81433} 38$ 69-84 For the average ophthalmologist the concept is rarely used in clinical practice because of the daunting trigonometry involved, producing a result which seems remote from the refraction actually presented by the patient.

The basis for all the methods of vector analysis is the theory of obliquely crossed cylinders originally described by Stokes. ${ }^{63}$ Naylor suggested that the formula could be used to determine the difference in refraction brought about by surgery. ${ }^{69}$

The principle assumes that a theoretical spherocylinder, the surgical induced astigmatism (SIA or $\mathrm{C}_{\text {SURG }} \times \beta^{\circ}$ ) is "crossed" with the preoperative refraction to produce the postoperative refraction (Fig 4, equation 8 ).

Figure 4 shows the graphical solution for the resultant of two obliquely crossed cylinders where the SIA equals the initial refraction minus the final refraction.

The "law of cosines" was further promoted by Jaffe and Clayman $^{38}$ and has resulted in a many subsequent publications about methods of calculation of the SIA. ${ }^{14} 33384569-84$ The main problem encountered is that the standard axis notation for cylinders (Axint, adopted at the 1950 International Federation of Ophthalmic Societies) only ranges from 0 to $180^{\circ}$. The formula as you can see addresses this by doubling the angle of astigmatism, but care is required when using the tangent function to determine the axis of the SIA and needs an understanding of when a $180^{\circ}$ correction is required.

On its own the SIA vector does not reflect the actual refractive outcome in any tangible way for the patient and surgeon alike. The reduction of astigmatism, which is a spatial entity that has curvatures in more than one plane, into a unidirectional arrow on a polar plot not only results in the loss of data but also introduces its own distortion of reality. ${ }^{85}$ This is because the SIA vector is only a theoretical

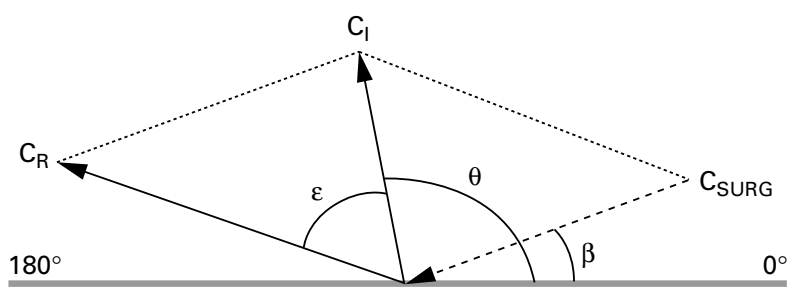

Figure 4 Diagram demonstrating the principle of vector analysis of the change in the astigmatic refraction following surgery. The arrow direction represents the axis of astigmatism and the length the magnitude. The principle assumes that a theoretical spherocylinder, the surgical induced astigmatism (SIA or $C_{\text {SURG }} \times \beta^{\circ}$ ) is "crossed" with the preoperative refraction to produce the postoperative refraction ${ }^{69}: S_{I} / C_{I} \times \theta^{\circ}+S_{S U R G} / C_{\text {SURG }}$ $\times \beta^{\circ}=S_{R} / C_{R} \times(\theta+\varepsilon)^{\circ}, C_{S U R G}=\left(C_{I}^{2}+C_{R}{ }^{2}-2 C_{I} C_{R} \cos 2 \varepsilon\right), S_{C V I}=\left(C_{t}\right.$ $\left.+C_{\text {SURG }}-C_{R}\right) / 2, \sin 2 \beta=\left(C_{R} / C_{\text {SURG }}\right) \sin 2 \varepsilon, S_{\text {SURG }}=S_{R}-S_{I}-S_{C Y L} ; C_{I}$ is the initial or preoperative astigmatism vector at $\theta^{\circ}$ axis (in "plus" cylinder notation), $C_{R}$ is the resultant or postoperative astigmatism vector at $\theta+\varepsilon^{\circ}$ axis ("plus" cylinder notation), $C_{\text {SURG }}$ is the surgically induced astigmatism vector (SIA, a theoretical construct) at $\beta^{\circ}$ axis (in "minus" cylinder notation), $S_{C Y L}$ is the spherical equivalent of all the cylindrical components. 
construct and has no structural existence. Vector analysis alone does not provide any indication of the relative value of the surgical procedure. The magnitude and orientation of astigmatism WTR or ATR is better described by the actual refraction or keratometry of the patient.

Vector analysis is a mathematically correct method of describing the relation between the initial and resultant cylinder. It provides information about the process by which the surgical outcome (the resultant cylinder) was achieved. However, for the surgeon in particular, the surgical vector alone does not really provide practical information about the surgical error. To be useful the surgical vector requires further translation.

\section{Optical decomposition of the cylinder}

Although Gartner ${ }^{86}$ from Australia was the first to describe the principle of optical decomposition of the cylinder, Humphrey recognised and capitalised on its utility before others. Humphrey's work has only recently been described in the ophthalmic literature although the principle of astigmatic decomposition was an innovative part of the Humphrey vision analyser patented in $1977 .{ }^{87} 88$ Humphrey stated that any spherocylinder may be expressed as the mean refractive error (that is, the spherical equivalent) in conjunction with two cross cylinders fixed at $0,90^{\circ}\left(\mathrm{J}_{0}\right)$ and at $45,135^{\circ}\left(\mathrm{J}_{45}\right)$. This can be achieved as follows ${ }^{16}{ }^{88}$ :

$$
\begin{aligned}
& \mathrm{S}_{\mathrm{EQ}}=\mathrm{S}+\mathrm{C} / 2 \\
& \mathrm{~J}_{0}=\mathrm{C} \times \cos 2 \theta \\
& \mathrm{J}_{45}=\mathrm{C} \times \sin 2 \theta
\end{aligned}
$$

where $\mathrm{S}$ is the spherical power and $\mathrm{C}$ is the cylinder power at $\theta^{\circ}$ axis.

Faced with the problem of analysing simultaneous changes in both direction and magnitude of astigmatism and acknowledging that vector analysis alone was not particularly useful, Cravy also suggested a method of astigmatism analysis that used optical decomposition of the astigmatism (apparently independently of Gartner's and Humphrey's work)..$^{56}$

Cravy reduced the keratometric astigmatism into an $\mathrm{x}$ or ATR and y or WTR component (equation 11, Fig 5).

$$
\begin{aligned}
& x=M \times \cos \theta \\
& y=M \times \sin \theta
\end{aligned}
$$

where $M$ is the magnitude of astigmatism and $\theta^{\circ}$ is the axis of astigmatism.

He then used these polar coordinates to derive a unitary number $(\Delta \mathrm{K})$ that described the astigmatism in terms of a WTR or ATR change. This required assigning a plus or minus to the polar value depending upon the change in the $\mathrm{x}$ or $\mathrm{y}$ value as a result of the surgery. Although this method assigned a relative value to the astigmatism, it was awkward to program for computers and only referred to a change in the astigmatism $(\Delta \mathrm{K})$.

Taking the concept of optical decomposition further, Naeser was able to demonstrate a simple mathematical relation that assigned a relative value to the astigmatism. He called this value the polar value of net astigmatism (KP). ${ }^{82} 838589-91$

The KP value was described a number of ways previously (equation 12), but more recently Naeser further modified this formula to calculate the polar value referable to the surgical plane (that is, the meridian on the cornea where the surgical wound was placed or aligned). So changes in the astigmatism projected on the steeper meridian are called "with the power" (WTP) and "against the power" (ATP) when projected onto the flatter meridian (rather than just to the $90^{\circ}$ degree meridian as before) ${ }^{85}$ :

$$
\mathrm{AKP}=\mathrm{M} \times\left(\sin ^{2}[\alpha+90]-\beta\right)+\cos ^{2}([\alpha+90]-\beta)
$$

where $M$ is the magnitude of astigmatism, $\alpha$ is the power meridian of net astigmatism (that is, $\alpha+90$ is the axis of astigmatism), and $\beta$ is the direction of the surgical plane (that is, the axis about which the surgical wound was placed), so AKP is the astigmatic polar value of net astigmatism.

So when the wound is placed at the 12 o'clock position the result is as before. To examine the WTR/ATR relation $\beta$ is denoted as $90^{\circ}$ regardless of the surgical plane.

In the analysis of a surgical result the polar value change "on" the surgical axis will provide an index of the efficacy, and the "off" the surgical axis astigmatism (that is, the net corneal astigmatism) an index of the accuracy of the refractive surgery.

Kaye et al suggested that a simple measure that reflects the surgical accuracy (SA) of a procedure could be expressed as the ratio of the "effectiveness" of the SIA vector to the sum of the SIA and resultant astigmatism $\left(\mathrm{C}_{\mathrm{R}}\right){ }^{78}$ The "effectiveness" of the SIA ( $\mathrm{C}_{\text {SURG }}$ ) was defined as the net effect of the SIA vector at $90^{\circ}$ to the initial astigmatism $\left(\mathrm{C}_{\mathrm{I}}\right)$. This was calculated by subtracting the decomposition of the SIA vector to an axis at $90^{\circ}$ from the initial astigmatism (equation 14, Fig 3). The maximum SA will be 1.0 when ${ }^{\prime} C_{\text {SURG }}$ equals $C_{\text {SURG }}$ thus $C_{R}$ is zero. Any axis misalignment or magnitude error would produce an SA of less than 1.0; however, the relative contribution of either of these two errors would not be distinguishable.

Olsen and Dam-Johansen described how the surgical vector between the initial and resultant cylinder vectors could be optically decomposed into the WTR and WTR meridians (similar to the Cravy method). ${ }^{84}$ This was to allow for the simultaneous presentation of magnitude and direction over time. Although Olsen's method highlights the need to translate the surgical vector into something meaningful and provides a relative value to the results of vector analysis, it still only describes the process rather than the outcome of the surgery. The translation fails to provide the necessary information about the surgical error of the procedure for the individual patient.

In an elegant synthesis of optical decomposition methods, Naeser and Behrens recently demonstrated that

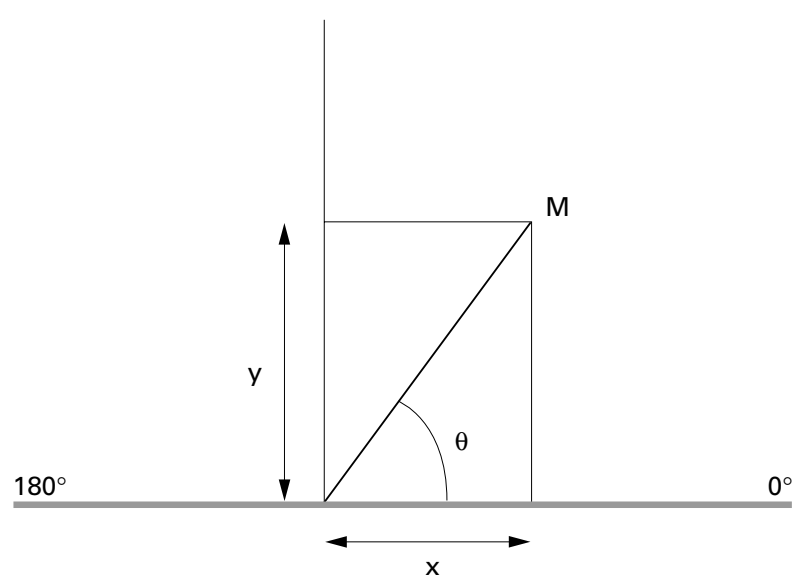

Figure 5 Diagram demonstrating the principle of decomposition of the astigmatic refraction into $x$ and $y$ values. Cravy ${ }^{56}$ suggested that cylinder (or astigmatism) of $M$ magnitude at $\theta^{\circ}$ axis maybe characterised by a " $y$ " magnitude at $90^{\circ}$ axis $(y=M \sin \theta)$ and an " $x$ " magnitude at the $0-180^{\circ}$ axis $(x=M \cos \theta)$. Naeser described a single summary value for the astigmatism which he called the polar value of net astigmatism $(K P){ }^{82} 83858991$ This was originally calculated as ${ }^{89}: K P=M \times(\sin \theta \mid$ $-|\cos \theta|)$, but modified later to $0^{\circ 0}: K P=M \times\left(\sin ^{2} \theta-\cos ^{2} \theta\right)$, where $M$ is the magnitude and $\theta$ is the axis of astigmatism, and KP is the polar value referable to the $90^{\circ}$ meridian (ie, encompassing the WTR and ATR concept). When $\sin \theta>\cos \theta,(i e, y>x)$, the more WTR the astigmatism and the more positive the polar value. Conversely when $\sin \theta<\cos \theta$ (ie, $y$ $<x)$ the more ATR the astigmatism and the more negative the polar value. 
the calculation of two polar values $45^{\circ}$ apart where equivalent to Humphrey's $\mathrm{J}_{\mathrm{o}}$ and $\mathrm{J}_{45}$ (equation 15). ${ }^{83}$

$$
\begin{aligned}
& \mathrm{KP}(90)=\mathrm{M} \times \cos 2 \theta=\mathrm{J}_{0} \\
& \text { and } \\
& \mathrm{KP}(135)=\mathrm{M} \times \sin 2 \theta=\mathrm{J}_{45}
\end{aligned}
$$

Naeser and Behrens then showed that there is a nexus between polar values and vector analysis. After determining the $\mathrm{KP}(90)$ and $\mathrm{KP}(135)$ values for the preoperative $\left(C_{I}\right)$ and postoperative $\left(C_{R}\right)$ astigmatism the SIA is simply calculated as:

$$
\begin{aligned}
& \text { SIA } \mathrm{KP}(90)=\mathrm{C}_{\mathrm{I}} \mathrm{KP}(90)-\mathrm{C}_{\mathrm{R}} \mathrm{KP}(90) \\
& \text { and } \\
& \text { SIA } \mathrm{KP}(135)=\mathrm{C}_{\mathrm{I}} \mathrm{KP}(135)-\mathrm{C}_{\mathrm{R}} \mathrm{KP}(135)
\end{aligned}
$$

where SIA is the surgically induced astigmatism, $\mathrm{C}_{\mathrm{I}}=$ the initial cylinder, and $\mathrm{C}_{\mathrm{R}}=$ the resultant cylinder (the magnitude and direction of the SIA vector can be found using the Humphrey notation re-conversion formulas, equation 10).

Using a different approach, Thibos et al also demonstrated the nexus between methods of optical decomposition of the cylinder and vector analysis. ${ }^{92}$ They describe the spherocylinder using Fourier analysis of the power profile of the refractive surface. Fourier analysis transposes a complex waveform into a constant and harmonically related sine and cosine waves - the constant being the spherical lens power, and the harmonic being the pure cylinder power (equation 17).

In fact the cylinder power represents a Jackson cross cylinder where the mean spherical equivalent is zero, and the cylinder power $\mathrm{J}=\mathrm{C} / 2$. Raasch describes the transformation of the spherocylinder power as a sum of 3 component terms - the spherical equivalent $\left(\mathrm{S}_{\mathrm{EQ}}=\mathrm{S}+\mathrm{J}\right)$, cosine astigmatism (Cs, the WTR/ATR component) and sine astigmatism ( $\mathrm{Sn}$, the oblique astigmatism) (equation 18, Fig 6) so that $^{93}$ :

$$
\mathrm{P}=\left[\begin{array}{l}
\mathrm{S}_{\mathrm{EQ}} \\
\mathrm{Cs} \\
\mathrm{Sn}
\end{array}\right]=[\mathrm{S}+\mathrm{J}-\mathrm{J} \times \cos 2 \theta-\mathrm{J} \times \sin 2 \theta]
$$

where $\mathrm{P}$ is spherocylindrical power, $\mathrm{S}$ the power of the sphere, $\mathrm{J}$ half the cylinder power (C), and $\theta$ the axis of $\mathrm{C}$.

The similarities of the Fourier transform to the Naeser formulas for $\mathrm{KP}(90)$ and $\mathrm{KP}(135)$, and the Gartner/ Humphrey method of decomposition are apparent. Fourier transformation also provides a nexus with the power matrix method of astigmatism analysis previously described (equation 19). ${ }^{74} 75$

The use of Fourier analysis extends beyond simple astigmatism. Raasch and others have demonstrated that

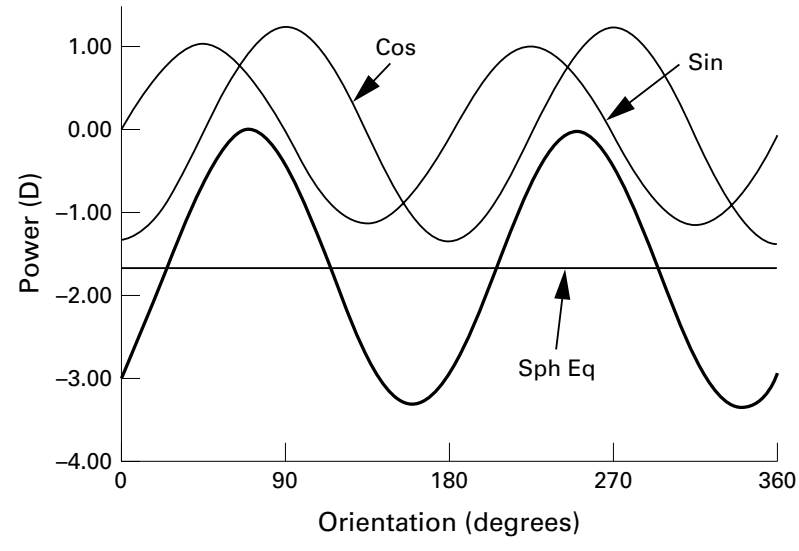

Figure 6 Diagram of the Fourier decomposition of a spherocylindrical lens $(S=$ plano $/ C=-3.25 \times \theta=70)$. The $360^{\circ}$ lens surface power (ie, for all meridians) is represented by the thick line. The three Fourier component terms are: a spherical equivalent $\left(S_{E Q}=S+C / 2\right)$, a cosine astigmatism term $(\mathcal{F} \times \cos 2 \theta)$, and sine astigmatism term $(\mathcal{F} \times \sin 2 \theta)$ where $\mathcal{F}=C / 2 .{ }^{93}$
Fourier analysis transforms the complex representations of corneal curvature produced by corneal topographic analysers from videokeratographs. ${ }^{94-98}$ With this method the topographic data are reduced to spherical equivalent power, and harmonics of decentration (first), regular astigmatism (second), and irregular astigmatism (third or higher order). This not only provides a powerful method of astigmatism analysis of complex data, but also a reliable method of data compression.

By using two polar values or the sin/cos Fourier values the astigmatism may be more completely characterised. For example, calculating a polar value in the plane of the incision will indicate the magnitude effect of the surgery - a positive value indicates steepening of the surgical meridian a negative value indicates flattening. Calculating another polar value at $45^{\circ}$ to the surgical plane will indicate the degree of cylinder rotation induced by the surgery - the larger the value, the greater the rotation with a zero value indicating no rotation.

Optical decomposition methods are attractive because the cylinder (expressed as magnitude and direction) is translated into two standard reference points (two magnitudes). Naeser's method in particular demonstrated that these methods can produce a relative value consistent with the WTR/ATR concept. Assigning a relative value enables one to make a meaningful comparison of the astigmatic outcomes between groups of patients.

\section{Other methods of analysis of the astigmatic effect of surgery}

The final result of refractive surgery may be influenced by the healing response, but the initial refractive outcome is determined by the accuracy of the axis alignment, and the quantity of change induced by the surgical procedure. Although both the components of the surgical error are interdependent, any axis misalignment will produce a magnitude effect of its own which, as previously discussed, will be proportional to the magnitude of cylindrical power produced by the surgical manoeuvre. To assess the effect of the procedure the surgeon would wish to know the error in achieving the target astigmatism - that is, was the axis placement correct and the quantity of the procedure enough?

The general aim of refractive surgery is to reduce the astigmatism. Conceptually it is easiest to consider the astigmatism in "plus cylinder" notation, so that the surgery then acts as if adding a "minus cylinder." When expressed as vectors, the surgical cylinder arrow would point in the opposite direction to the initial cylinder arrow. Vector analysis can now be usefully employed using this concept because the surgical error can be determined by the simple subtraction of the surgical vector from the initial cylinder vector. ${ }^{34}$ This will provide the magnitude $\left(\mathrm{C}_{\text {ERROR }}\right)$ and angle $(\phi)$ error of the surgery (equation 20, Fig 7).

Alpins also introduced the concept of "target induced astigmatism" (TIA), highlighting the concept of a planned astigmatic outcome as an integral part of modern cataract and refractive surgery. ${ }^{33}$ TIA was described as the cylinder vector of the desired change intended by the surgery, enabling the surgeon to match it with the SIA to determine the success or otherwise of the surgery. The surgical error can also be determined with regard to the planned resultant cylinder, the TIA (or planned) vector is subtracted from the surgical vector.

The concept of the surgical error of a procedure calculated from the vector analysis provides the surgeon with practical data to understand how the surgical process has produced the resultant cylinder. This of course is only valid in the early postoperative period before the healing response has modified the initial result of the surgery. 

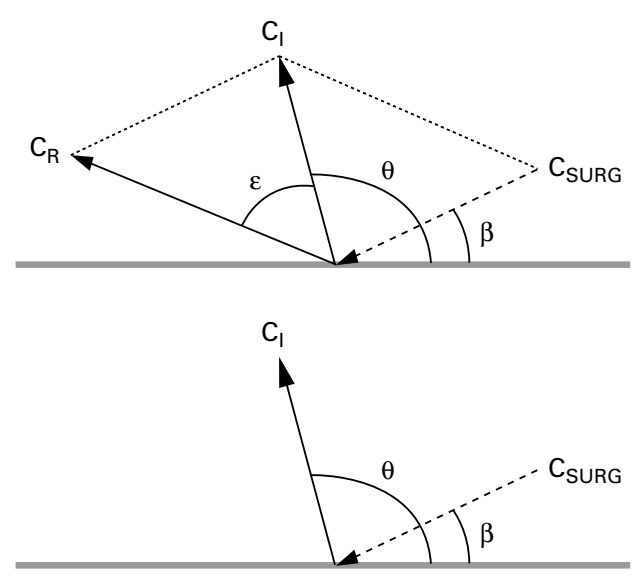
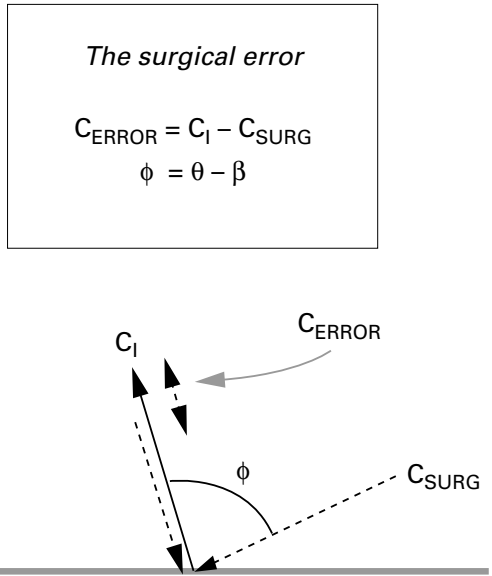

Figure 7 Diagram demonstrating the use of the vector representation of the astigmatic refraction to determine the quantities of surgical error. The magnitude error $\left(C_{\text {ERROR }}\right)$ is the simple subtraction of the absolute $C_{S U R G}$ magnitude from the absolute $C_{I}$ magnitude in dioptres cylinder. The direction or axis error $(\phi)$ is the $C_{S U R G}$ axis $(\beta)$ in minus cylinder notation from the $C_{I}$ axis $(\theta)$ in plus cylinder notation. ${ }^{34}$

\section{Statistical analysis of astigmatic changes after surgery}

Lack of critical evaluation of the utilisation of the surgical vector has resulted in its adoption as the de facto standard used in most reports concerning the surgical management of astigmatism. ${ }^{91}{ }^{99-103}$ Rather than describing an outcome, vector analysis best describes the process producing the surgical outcome. As a process measure it is only a conceptualisation relevant to the individual patient and not particularly useful as a population statistic, largely because it does not assign a value to the outcome. Moreover, Toulemont demonstrated that the formulas used to calculate the vectors are non-linear and introduce errors when using standard statistical analysis. ${ }^{76}$

Process measures relate to the events that produce an outcome. Accuracy is generally indicated by the mean effect produced by the event, whereas precision is indicated by the spread of the means (the standard error). However, the actual outcome (for example, the manifest postoperative refraction) is a more meaningful way to interpret the effect of a surgical procedure in population terms, particularly when comparing a number of different processes attempting to produce the same desired result. None the less, a meaningful result can only be found if a relative value is assigned to each outcome.

Serial measurements present particular difficulties in analysis. ${ }^{104}$ If chosen incorrectly the statistical the analysis often fails to answer clinically relevant questions. The use of the change in vector analysis over time is conceptually invalid, because the unlike the initial surgical event, the wound healing process is continuous. Mathews et al argue that the commonly used comparison method of a series of $t$ tests at each time point is flawed for three main reasons. ${ }^{104}$ The first is that the curve joining the means may not be a good descriptor of a typical curve for an individual. Secondly, the analysis does not take account of the fact that measurements at different time points are from the same subjects so are not independent measures and, lastly, successive observations on a given subject are likely to be correlated. They suggest that a more appropriate method is to choose a suitable summary of the response of an individual then analyse these summary measures as if they were raw data using simple statistical techniques. However, choosing one or more clinically appropriate summary measures from a time series requires care.

Summary measures such as the peak postoperative astigmatism, the final stabilised postoperative astigmatism (along with the proportion of WTR versus ATR), and the rate of change in the postoperative astigmatism would be appropriate for post-cataract surgery. The time to achieve a stable refraction would also be appropriate if sufficient measurements are made over the critical time period. For refractive surgery, such as arcuate keratotomy and excimer laser PRK outcome measures such as the surgical error (degree of axis misalignment and undercorrection or overcorrection of the cylinder magnitude) would be appropriate, as would the final stabilised postoperative refraction.

Even once the appropriate summary measure has been determined, the analysis of refractive changes is further compounded by the fact that the refraction consists of the sphere, cylinder and axis-all of which may change with time. For this reason optical decomposition methods are useful summary measures. Not only do they reduce the astigmatism from magnitude and direction down to two magnitudes it is also possible to assign a relative value to produce one summary value.

Bennett and Rabbetts suggested that the optical decomposition method of Humphrey was an appropriate method to determine the mean of any number of refractions, ${ }^{14}$ which was also the basis of Olsen's method ${ }^{84}$ and Naeser's most recent method. ${ }^{83} 91$ Each one of the three components could be separately summed, and the individual refractions first separated into groups of WTR or ATR if necessary. Cravy's and Naeser's approaches produced a single polar value to characterise the astigmatism and Kaye et al also demonstrated a method of producing a single summary value..$^{56883858990}$ Although each is an elegant compromise, these methods compress the data and are insensitive to oblique astigmatism. Polar values may be appropriate summary measures but they are inappropriate for sequential analysis at individual time points for the reasons already outlined.

However, the problem with all simple analysis is the difficulty in producing a standard deviation for a number of refractions because separate analysis of each component is statistically invalid. ${ }^{104}$ The statistical methods must make full and joint allowance for all the components of the refraction and may be best achieved by the use of multivariate methods of statistical analysis. Generally, three approaches to the problem have been described. For the cylinder power and axis alone others have used the Hoteling $\mathrm{T}^{2}$ statistic, ${ }^{105}$ or bivariate probabilistic analysis. ${ }^{77}$ For sphere and cylinder refractions Harris suggests converting the refraction to a power matrix and using his $w$ statistic and $\mathrm{F}$ distribution to compare the groups. ${ }^{106} 107$ Note, however, a relative value is not assigned using any of these methods.

Most methods suggested by others double the axis of astigmatism for analysis so that the ATR astigmatism values that are separated with the standard axis notation 

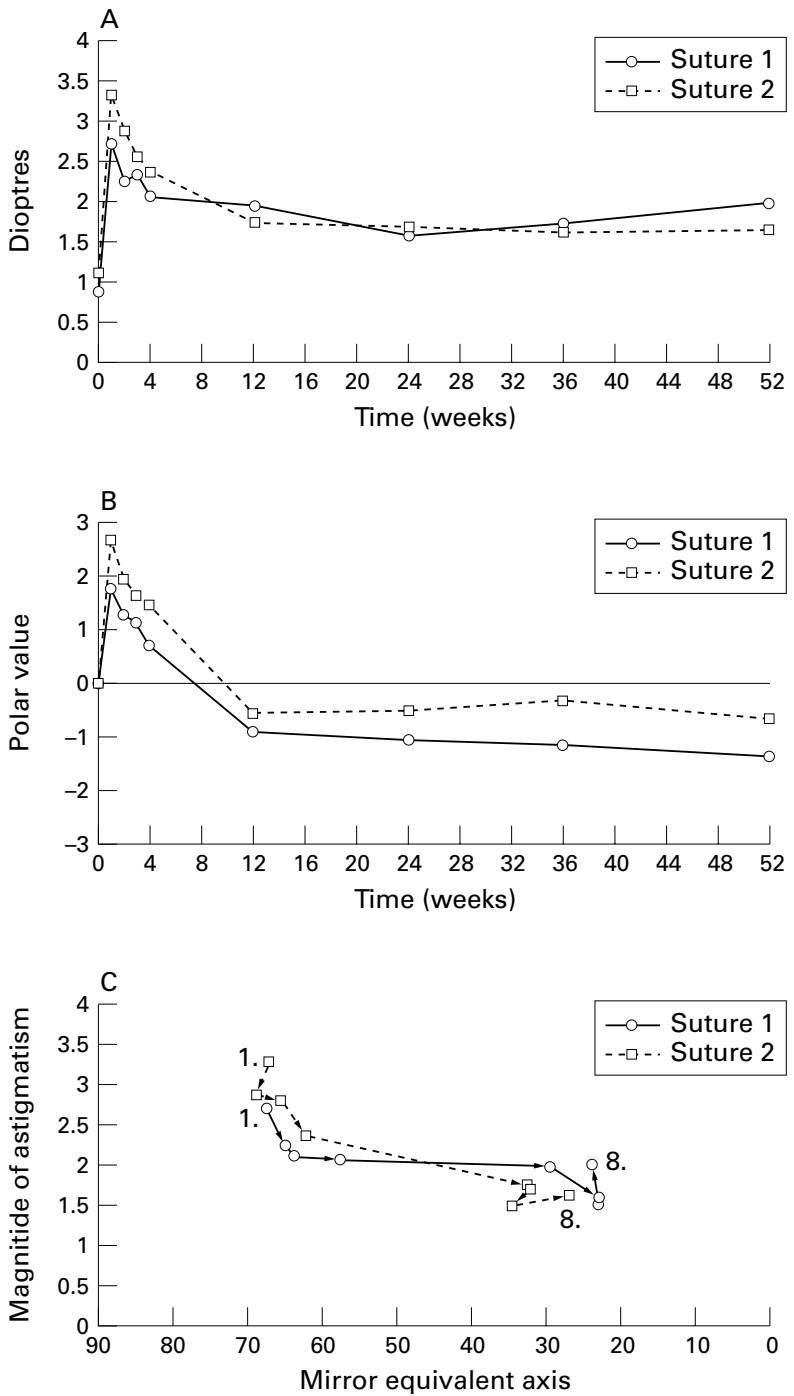

Figure 8 Methods of presenting astigmatism data. The same base data set is used for all the methods of presentation shown in Figures 8, 9, and 10. The data are from two groups of patients who had extracapsular cataract surgery. (A) The change in mean magnitude of astigmatism. (B) The change in the mean Naeser polar value (positive values are with the rule, negative values against the rule). (C) The change in the "expectancy" of astigmatism from 1 week postoperative (no 1) to 12 months postoperatively (no 8) using the "by the rule" or mirror equivalent axis conversion. The "expectancy" is a statistically correct bivariate (or simultaneous) calculation of the magnitude and axis for the grouped astigmatism data (as opposed to the incorrect method of calculating the simple mean of the magnitude or axis independently). This was calculated using the contingency table method of Toulemont. ${ }^{78}$ The axis values were first converted to mirror equivalent values as shown in Table 2.

are brought together by the $360^{\circ}$ polar transformation. Another method of addressing the problem of the split ATR astigmatism values is to transform those values above $90^{\circ}$ into "mirror equivalent" values less than $90^{\circ}$. Converting to mirror equivalent values bring the ATR values together, but unlike the double angle method, the oblique astigmatism values are also brought together so that all the values are conveniently presented in one quadrant (see Fig $8 \mathrm{C}$ and Table 2). For example, an angle of $175^{\circ}$ would convert to $5^{\circ}, 135^{\circ}$ to $45^{\circ}$, and $100^{\circ}$ to $80^{\circ}$. Although this results in some data compression, it is clinically relevant
Table 3 Examples of astigmatism power ('Pa) calculated for various "by the rule" axis values of $\mathcal{F}$ astigmatism from 1.00 to $5.00 \mathrm{D}$

\begin{tabular}{llllllllllll} 
Dioptres & $90^{\circ}$ & $80^{\circ}$ & $70^{\circ}$ & $60^{\circ}$ & $50^{\circ}$ & $45^{\circ}$ & $40^{\circ}$ & $30^{\circ}$ & $20^{\circ}$ & $10^{\circ}$ & $0^{\circ}$ \\
\hline 1.00 & 0.50 & 0.42 & 0.36 & 0.32 & 0.30 & 0.29 & 0.30 & 0.32 & 0.36 & 0.42 & 0.50 \\
2.00 & 1.00 & 0.84 & 0.72 & 0.63 & 0.59 & 0.59 & 0.59 & 0.63 & 0.72 & 0.84 & 1.00 \\
3.00 & 1.50 & 1.26 & 1.08 & 0.95 & 0.89 & 0.88 & 0.89 & 0.95 & 1.08 & 1.26 & 1.50 \\
4.00 & 2.00 & 1.68 & 1.44 & 1.27 & 1.18 & 1.17 & 1.18 & 1.27 & 1.44 & 1.68 & 2.00 \\
5.00 & 2.50 & 2.10 & 1.80 & 1.58 & 1.48 & 1.46 & 1.48 & 1.58 & 1.80 & 2.10 & 2.50
\end{tabular}

Table 4 Examples of cosine astigmatism (Cs) calculated for various "by the rule" axis values of $\mathcal{F}$ astigmatism from 1.00 to $5.00 \mathrm{D}$

Dioptres $\quad 90^{\circ} \quad 80^{\circ} \quad 70^{\circ} \quad 60^{\circ} \quad 50^{\circ} \quad 45^{\circ} \quad 40^{\circ} \quad 30^{\circ} \quad 20^{\circ} \quad 10^{\circ} \quad 0^{\circ}$

\begin{tabular}{llllllllllll}
\hline 1.00 & 0.00 & 0.09 & 0.17 & 0.25 & 0.32 & 0.35 & 0.38 & 0.43 & 0.47 & 0.49 & 0.50
\end{tabular}

$\begin{array}{lllllllllllll}2.00 & 0.00 & 0.17 & 0.34 & 0.50 & 0.64 & 0.71 & 0.77 & 0.87 & 0.94 & 0.98 & 1.00\end{array}$

$\begin{array}{llllllllllll}3.00 & 0.00 & 0.26 & 0.51 & 0.75 & 0.96 & 1.06 & 1.15 & 1.30 & 1.41 & 1.48 & 1.50\end{array}$

$\begin{array}{llllllllllll}4.00 & 0.00 & 0.35 & 0.68 & 1.00 & 1.29 & 1.41 & 1.53 & 1.73 & 1.88 & 1.97 & 2.00\end{array}$

$\begin{array}{llllllllllll}5.00 & 0.00 & 0.43 & 0.86 & 1.25 & 1.61 & 1.77 & 1.92 & 2.17 & 2.35 & 2.46 & 2.50\end{array}$

and totally in keeping with the concept of astigmatism orientation. Not only does it allow a relative value for grouped data to be assigned at a glance, it greatly improves the method by which data can be presented.

Optical decomposition consistent with the Fourier analysis methodology is possible using the "by the rule" transformation of the cylinder axis:

$\mathrm{Sn}=\mathrm{J} \times \sin \left({ }^{\prime} \theta\right)$

'Cs $=\mathrm{J} \times \cos \left({ }^{\prime} \theta\right)$

where $\mathrm{J}=\mathrm{C} / 2$, half the cylinder power and ' $\theta$ is the "by the rule" or mirror equivalent axis.

For the whole refraction:

$$
\text { 'P }=\left[\mathrm{S}+\mathrm{J}-{ }^{\prime} \mathrm{Cs}-{ }^{\prime} \mathrm{Sn}\right]
$$

where $\mathrm{S}+\mathrm{J}=\mathrm{S}_{\mathrm{EO}}$ the spherical equivalent, and for the astigmatism power alone:

$$
' \mathrm{~Pa}=\left[\mathrm{J}-\mathrm{`C}^{-} \mathrm{`} \mathrm{Sn}\right]
$$

where 'Pa is the "by the rule" transformed astigmatism power.

Although `Pa may be a used as a summary measure, it does not produce a linear progression and deals with the problem of oblique astigmatism poorly. As can be seen in Table 3 not only are the values for the WTR and ATR axes equivalent, the more oblique values better weighted.

The "by the rule" cosine astigmatism (Cs) shown in Table 4 is also an inadequate summary measure. Although 'Cs increased for the magnitude of astigmatism as the axis changes from WTR to ATR, the progression is non-linear and all the $90^{\circ}$ values are null.

To produce a linear progression in which a single individual value for each astigmatism a simple rank could be assigned using the "by the rule" axis of astigmatism such that:

$$
\mathrm{R}=\mathrm{M}-\left({ }^{\prime} \theta / 400\right)
$$

where $M$ is the magnitude of astigmatism and ' $\theta$ the "by the rule" axis.

Although this method of ranking the astigmatism assigns a better value to the oblique astigmatism than the ATR astigmatism, $\mathrm{R}$ is easily computed by a spreadsheet. The effect of the $S_{\mathrm{EQ}}$ (equation 3) may also be computed by a spreadsheet to transform $\mathrm{R}$ to further delineate its relative value as part of the whole refraction.

Another method that may better encapsulate a relative value is by manually assigning a score to each patient's

Table 2 Transforming the astigmatism from 0-180 (Axint cylinder notation) to 0/180-90 ("by the rule" notation, ie, mirror equivalents). This allows the ATR and oblique astigmatism values to be grouped together. This may be computed with an if, then, else statement-eg, if $\theta>90$, then ' $\theta=180-\theta$, else $\theta=\theta$

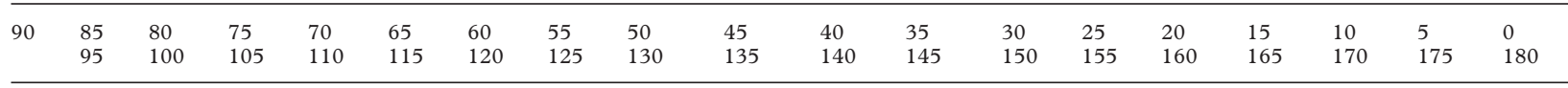


Table 5 An example of manually scoring the astigmatism to produce a summary measure for statistical analysis. The actual steps in the magnitude may be altered to suit the clinical situation requiring analysis. Smaller increments maybe suitable when larger numbers of patients are involved

\begin{tabular}{llll}
\hline $\begin{array}{l}\text { Magnitude } \\
\text { (D) }\end{array}$ & $\begin{array}{l}\text { WTR (axis } \\
\left.60-120^{\circ}\right)\end{array}$ & $\begin{array}{l}\text { ATR (axis 0-30, } \\
\text { and 150-180 })\end{array}$ & $\begin{array}{l}\text { OBL (axis 30-59 } \\
120-149^{\circ} \text {, and }\end{array}$ \\
\hline$>6$ & 20 & 21 & 22 \\
$5.25-6.00$ & 17 & 18 & 19 \\
$4.25-5.00$ & 14 & 15 & 16 \\
$3.25-4.00$ & 11 & 12 & 13 \\
$2.25-3.00$ & 8 & 9 & 10 \\
$1.25-2.00$ & 5 & 6 & 7 \\
$0.50-1.00$ & 2 & 3 & 4 \\
$<0.50$ & 1 & 1 & 1
\end{tabular}

$\mathrm{WTR}=$ with the rule astigmatism, $\mathrm{ATR}=$ against the rule astigmatism, $\mathrm{OBL}=$ oblique astigmatism.

refraction or astigmatism. This method assumes that a lower magnitude of astigmatism WTR is most desirable and that a higher magnitude oblique astigmatism is the least desirable outcome (Table 5).

The data generated by this scoring methods may be regarded as ordinal categorical (or continuous) data, amenable to analysis by a large number of well established statistical procedures, including multiple linear or logistic regression. Another advantage is that for any pair of scores, the higher is always clinically interpretable as the least desirable. This is not the case for most other methods.

\section{Data presentation}

Many of the aforementioned papers and others have suggested methods to present the data after cataract surgery. ${ }^{72}$ Like the problem with the analysis, displaying the concurrent change in magnitude and axis of astigmatism over time presents difficulties. A series of $360^{\circ}$ polar scatter plots may produce an overview of the spread of the data but poorly presents the mean data and separates the oblique astigmatisms. ${ }^{105} \mathrm{~A}$ plot of the magnitude of astigmatism alone is useful because this is the major component determining the quality of the refractive outcome (Fig 8A). The effect of the direction of the astigmatism combined with the magnitude over time may be demonstrated with plots of polar values (Fig 8B). More succinct graphs such as Figure $8 \mathrm{C}$ which use mirror equivalent values compress the data into one quadrant with each point representing the mean value at a particular time. Another method is to use balloon plots (Fig 9), the position relates to the direction and the size to the magnitude of the astigmatism - these can be plotted along a time line as is the convention. Frequently, histograms are a good way of comparing the summary measures (Fig 10). The magnitude and direction can be compared independently; alternatively a contingency table may be put into a three dimensional density plot. ${ }^{77}$ The surgical error is also conveniently plotted as a histogram for magnitude and cylinder error.

\section{Conclusion}

The astigmatic results of refractive surgery are best evaluated in terms of a relative value. In general, any residual astigmatism is best when "with the rule" and worst when oblique; however, the magnitude of the astigmatism is the predominant concern.

Vector analysis provides information about the process of the surgery and is most useful when translated into quantities of surgical error. However, the effect of wound healing is continuous and inappropriately summarised by vector analysis, which does not give a measure of outcome.

Because of the different effects of "with the rule" and "against the rule" astigmatism on vision, when comparing different groups or methods, the outcome is best evaluated using a summary measure that assigns a relative value to the result such as Naeser's or Cravy's method. However, neither of these methods adequately assesses obliquity of astigmatism.

Better evaluation of the effect of astigmatism axis requires the use of the "by the rule" or mirror equivalent axis notation, or by a manual scoring method to produce an outcome summary measure.

Thus, different methods of analysis are available to study the effect of surgery on astigmatism, several may be required to summarise both process and outcome.

Our thanks to Peter Lindsay, Bill Aylward, Julian Stevens, and Geoff Woodward for helpful discussions during the preparation of this paper. Data for Figures 8, 9 , and 10 were from a study funded by Davis and Geck. Our thanks to those authors who kindly provided reprints of their articles.

\section{Appendix}

Equations:

(1) The percentage distortion of anastigmatic lens ${ }^{14}$ :

$100 \times(d \alpha-d \beta) / d \beta$

where $\mathrm{d} \alpha$ is the dioptric power of the first principal focus of an astigmatic image and $d \beta$ is the dioptric power of the second principal focus.

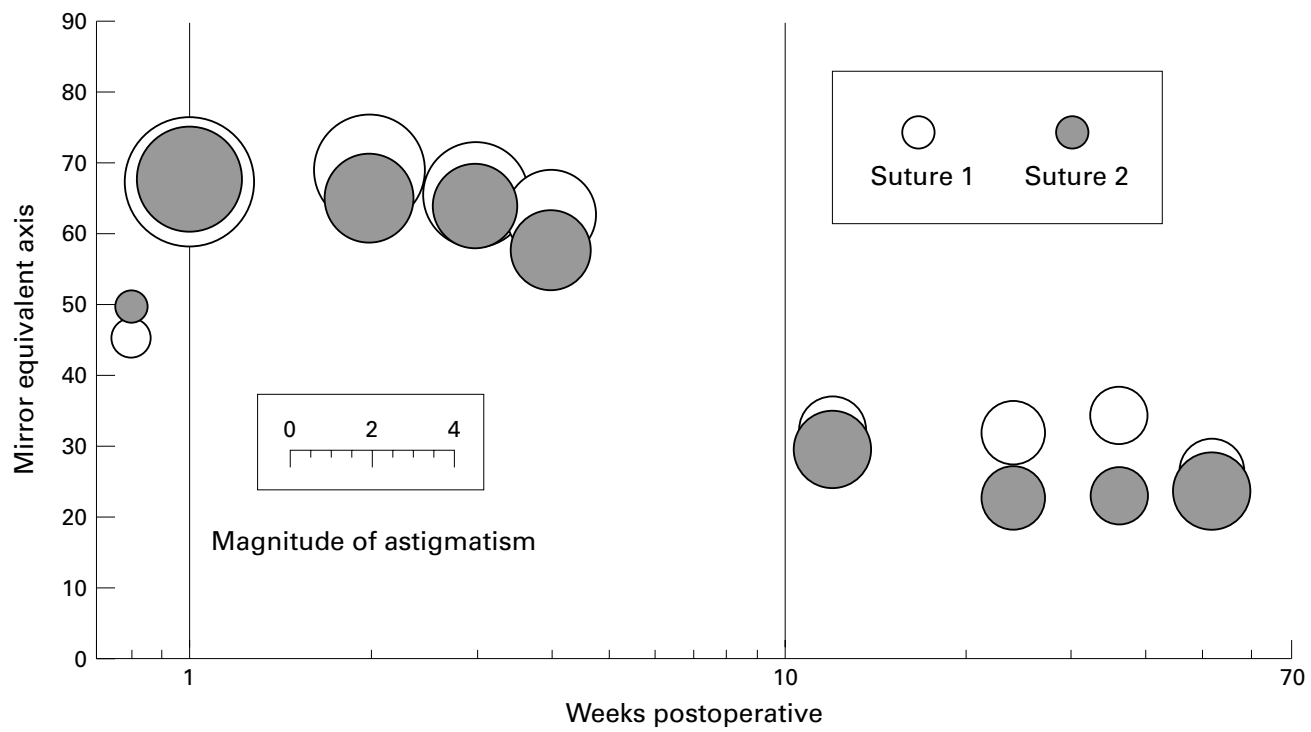

Figure 9 Methods of presenting astigmatism data. The same base data set is used for all the methods of presentation shown in figures 8, 9, and 10. The data are from two groups of patients who had extracapsular cataract surgery. The change in the "expectancy" of astigmatism regraphed as a balloon plot. 

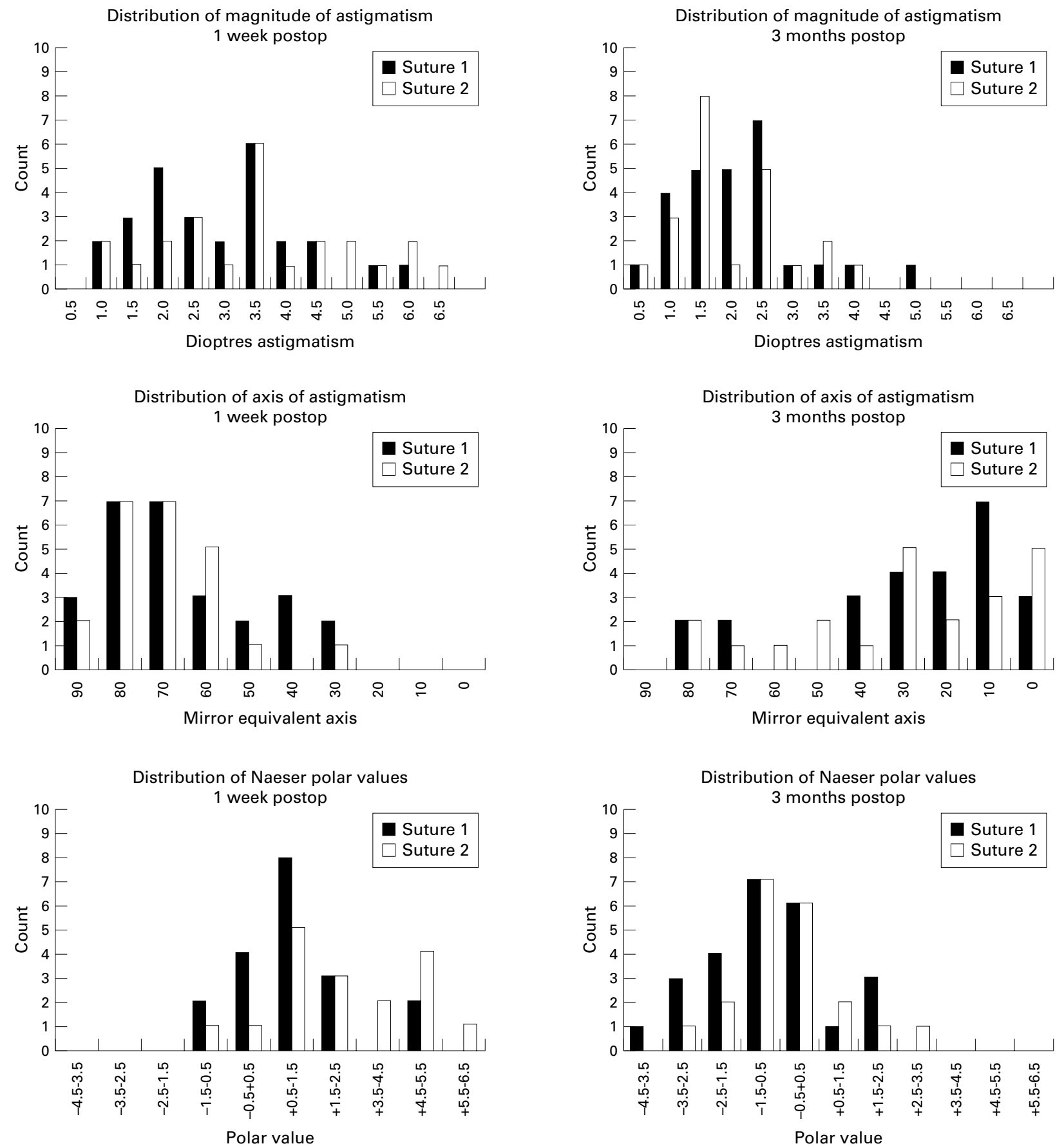

Figure 10 Methods of presenting astigmatism data. The same base data set is used for all the methods of presentation shown in figures 8 , 9, and 10. The data are from two groups of patients who had extracapsular cataract surgery. The change in magnitude and axis (converted to mirror equivalent values) of astigmatism and Naeser polar values plotted as frequency histograms at 1 week and 3 months postoperatively.

$$
\begin{aligned}
& \text { (2) Javal's rule }{ }^{142} \text { : } \\
& \mathrm{C}=1.25 \mathrm{M}-0.50
\end{aligned}
$$

where $\mathrm{C}$ is the cylindrical power in the spectacle correction and $\mathrm{M}$ is the magnitude of corneal astigmatism, which is regarded as positive with the rule (WTR) and negative against the rule (ATR).

(3) Spectacle cylinder power ${ }^{14} 3135{ }^{36}$ :

$$
\mathrm{C} \approx\left(1-2 d \mathrm{~S}_{\mathrm{EQ}}\right) \mathrm{M}
$$

where $d$ is the vertex distance of the correcting cylinder C, $\mathrm{S}_{\mathrm{EQ}}$ is the spherical equivalent and $\mathrm{M}$ is the magnitude of corneal astigmatism.

(4) The ideal cylinder for a given spherical equivalent ${ }^{25}$ :

$$
\mathrm{C}=-2 \mathrm{~S}_{\mathrm{EQ}}-0.50(\text { ie, } \mathrm{C}=- \text { sphere }-0.25)
$$

where $\mathrm{S}_{\mathrm{EQ}}$ is $-0.25 \mathrm{D}$ or less (ie, a myopic correction) and $\mathrm{C}$ is a plus cylinder, and

$$
\mathrm{C}=2 \mathrm{~S}_{\mathrm{EQ}}+0.50
$$

where $S_{\mathrm{EQ}}$ is greater than $-0.25 \mathrm{D}$ (ie, a hypermetropic correction).

(5) The effect of misalignment of a correcting cylinderthat is, the combined cylinder power and axis produced by two obliquely crossed cylinders ${ }^{1665-68}$ :

$$
(\mathrm{C} \sin \phi) \mathrm{DS} /-2 \mathrm{C} \sin \phi) \mathrm{DC} \text {, axis }(\theta+45+\phi / 2)
$$

where $\mathrm{C}$ the correcting cylinder is set at $\phi$ angle from the true axis $\theta, \mathrm{DS}=$ resultant sphere (dioptres), DC = resultant cylinder (cylinder). 
(6) The optimal cylinder power to minimise the residual astigmatism from axis misalignment of a correcting cylinder ${ }^{16}$ 65-68:

$\mathrm{C} \cos 2 \phi$

where $\mathrm{C}$ is the original full dioptric power of the correcting cylinder and $\phi$ is the angle the cylinder is rotated away from the correct position.

(7) If the "optimal value" for the correct cylinder power is used, the residual astigmatism is:

$\mathrm{C} \sin 2 \phi$

where $\mathrm{C}$ is the original full dioptric power of the correcting cylinder and $\phi$ is the angle the cylinder is rotated away from the correct position.

(8) The theoretical "astigmatic correction" of surgery-the surgical induced astigmatism (SIA or $\mathrm{C}_{\text {SURG }}$ ) is calculated by subtracting the initial refraction from the resultant refraction ${ }^{69}$ :

$$
\begin{aligned}
& \mathrm{S}_{\mathrm{I}} / \mathrm{C}_{\mathrm{I}} \times \theta^{\circ}+\mathrm{S}_{\text {SURG }} / \mathrm{C}_{\text {SURG }} \times \beta^{\circ}=\mathrm{S}_{\mathrm{R}} / \mathrm{C}_{\mathrm{R}} \times(\theta+\varepsilon)^{\circ} \\
& \mathrm{C}_{\text {SURG }}=\left(\mathrm{C}_{\mathrm{I}}^{2}+\mathrm{C}_{\mathrm{R}}{ }^{2}-2 \mathrm{C}_{\mathrm{I}} \mathrm{C}_{\mathrm{R}} \cos 2 \varepsilon\right) \\
& \mathrm{S}_{\mathrm{CYL}}=\left(\mathrm{C}_{\mathrm{I}}+\mathrm{C}_{\text {SURG }}-\mathrm{C}_{\mathrm{R}}\right) / 2 \\
& \sin 2 \beta=\left(\mathrm{C}_{\mathrm{R}} / \mathrm{C}_{\text {SURG }}\right) \sin 2 \varepsilon \\
& \mathrm{S}_{\text {SURG }}=\mathrm{S}_{\mathrm{R}}-\mathrm{S}_{\mathrm{I}}-\mathrm{S}_{\mathrm{CYL}}
\end{aligned}
$$

where $S_{I}$ and $C_{I}$ at $\theta^{\circ}$ axis (in "plus" cylinder notation) is the initial refraction, $S_{R}$ and $C_{R}$ at $\theta+\varepsilon^{\circ}$ axis ("plus" cylinder notation) is the resultant refraction, and $S_{\text {SURG }}$ and $\mathrm{C}_{\text {SURG }}$ at $\beta^{\circ}$ axis (in "minus" cylinder notation) is the difference in the refraction brought about by surgery, otherwise known as the surgically induced astigmatism SIA $\left(\mathrm{S}_{\mathrm{CYL}}\right.$ is the spherical equivalent of all the cylindrical components). (9) The optical decomposition of a spherocylinder into a spherical equivalent and a cross cylinder fixed at $0,90^{\circ}\left(\mathrm{J}_{0}\right)$ and at $45,135^{\circ}\left(\mathrm{J}_{45}\right)$ ("Humphrey" notation) ${ }^{1688}$ :

$$
\begin{aligned}
& \mathrm{S}_{\mathrm{EQ}}=\mathrm{S}+\mathrm{C} / 2 \\
& \mathrm{~J}_{0}=\mathrm{C} \cos 2 \theta \\
& \mathrm{J}_{45}=\mathrm{C} \sin 2 \theta
\end{aligned}
$$

where $\mathrm{S}$ is the spherical power, and $\mathrm{C}$ the cylinder power at axis $\theta^{\circ}$.

(10) The reconversion of "Humphrey" notation back to orthodox notation ${ }^{168}$ :

$$
\begin{aligned}
& \mathrm{C}= \pm\left(\mathrm{J}_{0}{ }^{2}+\mathrm{J}_{45}{ }^{2}\right) \\
& \theta=\arctan \left\{\left(\mathrm{C}-\mathrm{J}_{0}\right) / \mathrm{J}_{45}\right\} \\
& \mathrm{S}=\mathrm{S}_{\mathrm{EQ}}-\mathrm{C} / 2
\end{aligned}
$$

(11) Cravy's decomposition of the keratometric astigmatism $^{56}$ :

$$
\begin{aligned}
& x=M \cos \theta \\
& y=M \sin \theta
\end{aligned}
$$

where $M$ is the magnitude of astigmatism and $\theta$ is the axis of astigmatism, $\mathrm{x}$ the "against the rule astigmatism" component (ATR), and y "with the rule" (WTR) component.

(12) Naeser's polar value of net astigmatism (KP). This was originally given $\mathrm{as}^{89}$ :

$$
\mathrm{KP}=\mathrm{M} \times(|\sin \theta|-|\cos \theta|),
$$

but modified later to ${ }^{90}$ :

$$
\mathrm{KP}=\mathrm{M} \times\left(\sin ^{2} \theta-\cos ^{2} \theta\right)
$$

where $M$ is the magnitude and $\theta$ is the axis of astigmatism, and $\mathrm{KP}$ is the polar value referable to the $90^{\circ}$ meridian (that is, encompassing the WTR and ATR concept).

(13) Naeser's astigmatic polar value ${ }^{85}$ :

$$
\mathrm{AKP}=\mathrm{M} \times\left(\sin ^{2}[\alpha+90]-\beta\right)+\cos ^{2}([\alpha+90]-\beta)
$$

where $\alpha$ is the power meridian of net astigmatism (that is, $\alpha$ +90 is the axis of astigmatism) and $\beta$ is the direction of the surgical plane (that is, the axis about which the surgical wound was placed), so AKP is the astigmatic polar value of net astigmatism.
(14) Kay's summary measure, the surgical accuracy (SA) ${ }^{78}$ :

$$
\mathrm{C}_{\text {SURG }}=-\mathrm{C}_{\text {SURG }} \times \cos 2(\beta-\theta)
$$$$
\mathrm{SA}=\mathrm{C}_{\text {SURG }} /\left(\mathrm{C}_{\text {SURG }}+\mathrm{C}_{\mathrm{R}}\right)
$$

where ' $\mathrm{C}_{\text {SURG }}$ is the "effectiveness" of the surgically induced astigmatism (SIA) vector, $\mathrm{C}_{\mathrm{R}}$ the resultant astigmatism.

(15) Determining the Gartner/Humphrey cross cylinder astigmatism $(\mathrm{J})$ values using Naeser's AKP method of optical decomposition - the synthesis of optical decomposition methods ${ }^{83}$ :

$$
\mathrm{KP}(90)=\mathrm{M} \times\left(\sin ^{2}[\alpha+90]-\cos ^{2}[\alpha+90]\right)
$$

where $\alpha$ is the meridian of astigmatism and M the magnitude.

However where $\theta$ is the axis of astigmatism:

$\mathrm{KP}(90)=M \times\left(\sin ^{2}[\theta-90]-\cos ^{2}[\theta-90]\right)$

$=\mathrm{M} \times\left([-\cos \theta]^{2}-\left[\sin ^{2} \theta\right]\right)$

$=M \times\left(\cos ^{2} \theta-\sin ^{2} \theta\right)$

$=\mathrm{M} \times \cos 2 \theta$

$=\mathrm{J}_{0}$

and

$$
\begin{aligned}
& \mathrm{KP}(135)=\left(\left[M \times 1 / 2 \sin ^{2} \theta+1 / 2 \cos ^{2} \theta+\sin \theta \times \cos \theta\right]-\right. \\
& =M \times(2 \sin \theta \times \cos \theta) \\
& =M \times \sin 2 \theta \\
& =\mathrm{J}_{45}
\end{aligned}
$$

(16) Determining the SIA using polar values from Naeser's AKP method ${ }^{83}$ :

$$
\text { SIA } K P(90)=C_{I} K P(90)-C_{R} K P(90)
$$

and

$$
\text { SIA } \mathrm{KP}(135)=\mathrm{C}_{\mathrm{I}} \mathrm{KP}(135)-\mathrm{C}_{\mathrm{R}} \mathrm{KP}(135)
$$

where SIA is the surgically induced astigmatism, $\mathrm{C}_{\mathrm{I}}$ the initial cylinder, and $C_{R}$ the resultant cylinder (the magnitude and direction of the SIA vector can be found using the Humphrey notation re-conversion formulas as described earlier).

(17) Describing the power profile of the spherocylinder surface by Fourier decomposition ${ }^{92}$ :

the spherical equivalent is the constant

$$
\mathrm{S}_{\mathrm{EQ}}=\mathrm{S}+\mathrm{C} / 2
$$

$\mathrm{S}$ is the spherical power and $\mathrm{C}$ the cylinder power.

The pure cylinder power is the harmonic

$$
P_{\mathrm{CYL}}=\mathrm{C} / 2[\cos 2(\alpha-\theta)]
$$

where $\alpha$ is the meridian of the power (the meridian of the "astigmatism" is at $90^{\circ}$ ) and $\theta$ is the axis of astigmatism, so

$$
\mathrm{P}(\theta)=\mathrm{S}_{\mathrm{EQ}}+\mathrm{J} \times \cos (2[\alpha-\theta])
$$

because $\mathrm{J}=\mathrm{C} / 2$

(18) The power profile of a spherocylinder as a power matrix and decomposed by Fourier transformation ${ }^{93}$ :

$$
\mathrm{P}=\left[\begin{array}{l}
\mathrm{S}_{\mathrm{EQ}} \\
\mathrm{C}_{\mathrm{S}} \\
\mathrm{S}_{\mathrm{n}}
\end{array}\right]=[\mathrm{S}+\mathrm{J}-\mathrm{J} \times \cos (2 \theta)-\mathrm{J} \times \sin (2 \theta)]
$$

where Cs is the cosine astigmatism the WTR/ATR component, and $\mathrm{Sn}$ is the sine astigmatism also known as the oblique astigmatism, $\mathrm{S}$ is the power of the sphere, $\mathrm{J}$ is half the cylinder power $(\mathrm{C} / 2)$,

(19) The spherocylinderical lens $2 \times 2$ power matrix represented by a Fourier transform ${ }^{93}$ :

$$
\begin{aligned}
& F=\left[\begin{array}{ll}
f_{11} & f_{12} \\
f_{21} & f_{22}
\end{array}\right]=\left[\begin{array}{lr}
S+C \times \sin ^{2} \theta & -C \times \sin \theta \times \cos \theta \\
-C \times \sin \theta \times \cos \theta & S+C \times \cos ^{2} \theta
\end{array}\right] \\
& F=\left[\begin{array}{lr}
S_{\mathrm{EQ}}+C s & S n \\
S n & S_{E Q}-C s
\end{array}\right]
\end{aligned}
$$


(20) The surgical error ${ }^{34}$ :

magnitude of $\mathrm{C}_{\mathrm{ERROR}}=\mathrm{C}_{\mathrm{I}}-\mathrm{C}_{\mathrm{SURG}}$

axis error $\phi=\theta-\beta$

where $\mathrm{C}_{\mathrm{I}} \times \theta$ is the initial astigmatism, and $\mathrm{C}_{\mathrm{SURG}} \times \beta$ is the surgically induced astigmatism (SIA).

(21) Assigning a rank summary measure of the resultant astigmatism using a "by the rule" transformation of the axis of astigmatism:

$\mathrm{R}=\mathrm{M}-\left({ }^{\prime} \theta / 400\right)$

where $M$ is the magnitude of astigmatism, and ' $\theta$ is the "by the rule" axis of astigmatism.

NIGEL MORLET

Moorfields Eye Hospital, London, UK and Eye Surgery Foundation, Perth, Western Australia

DARWIN MINASSIAN

International Centre for Eye Health, Institute of Ophthalmology, London, UK

JOHN DART

Moorfields Eye Hospital, London, UK

Correspondence to: Nigel Morlet, 592 Stirling Highway, Mosman Park, WA, 6012, Australia

1 Oevres de Young edited by $M$ Tscherning.

2 Airy GB. On a peculiar defect in the eye, and a mode of correcting it. Transactions of the Cambridge Phil Soc 1827;2:267-71.

3 Knapp H. Ueber die asymmetrie des auges in seinen versschiedenen meridiansystemen. von Graefe's Arch fur Ophthalmol 1862;8:185.

4 Donders FC. Astigmatismus und cylindrische gläser. 1862, Verlag von Hermann Peters, Berlin.

5 Donders FC (trans WD Moore). On the anomalies of accommodation and refraction of the eye. London: New Sydenham Society, 1864.

6 Snellen H. Die richtung der hauptmeridian de astigmalischen auges. von Graefe's Arch fur Ophthalmol 1869;15:199.

7 Bates WH. A suggestion of an operation to correct astigmatism. Arch Ophthalmol 1894;23:9-13.

8 Lans LJ. Experimentelle untersuchugen über entstehung von astigmatismus durch nich-perforirende corneawunden. von Graefe's Arch fur Ophthalmol $1898 ; 45: 117-152$

9 Sato T. Experimental study on surgical correction of astigmatism (in Japanese). funtendo Kenkyukai-zasshi 1943;589:37-39.

10 Sato T. Posterior incision of the cornea. Surgical treatment for conical cornea and astigmatism. Am f Ophthalmol 1950;33:943-948.

11 Troutman RC. Microsurgery of the anterior segment of the eye. New York: Mosby, 1977.

12 Troutman RC. Improved techniques refractive surgery for astigmatism. Cornea 1982;1:57

13 Bennett AG. Emsley and Swaine's ophthalmic lenses. Vol 1. London: Hatton Press, 1968

14 Bennett AG, Rabbetts RB. Clinical visual optics. London: Butterworths, 1982

15 Duke-Elder S, Abrams D. Ophthalmic optics and refraction. System of ophthalmology. Vol 5. London: Henry Kimpton, 1970.

16 Guyton DL Prescribing cylinders: the problem of distortion. Surv Ophthalmol 1977;22:177-88.

17 Culbertson $\mathrm{H}$. Binocular astigmatism. FAMA 1888;11:622-5

18 Culbertson H. Binocular astigmatism. Am $\mathcal{F}$ Ophthalmol 1888;5:117-23.

19 Lippincott JA. On the binocular metamorphopsia due to correcting glasses. Arch Ophthalmol 1889;18:18-30.

20 Burian HM. Influence of prolonged wearing of meridional size lenses on spatial localization. Arch Ophthalmol 1943;30:645-66.

21 Ogle KN, Madigan LF. Astigmatism at oblique axes and binocular stereoscopic spatial localisation. Arch Ophthalmol 1945;33:116-27.

22 Bradbury JA, Hillman JS, Cassells-Brown A. Optimal postoperative refraction for good unaided near and distance vision with monofocal intraocular lenses. Br f Ophthalmol 1992;76:300-2.

23 Peters HB. The relationship between refractive error and visual acuity at three age levels. Am f Optom 1961;38:194-8.

24 Huber C. Myopic astigmatism as a substitute for accommodation in psuedophakia. Doc Ophthalmol 1981;52:123-78.

25 Datiles MB, Gancayco T. Low myopia with astigmatic correction gives cataract surgery patients good depth of focus. Ophthalmology 1990;97:922-6.

26 Sawusch MR, Guyton DL. Optimal astigmatism to enhance depth of focus after cataract surgery. Ophthalmology 1991;98:1025-9.

27 Trindale F, Olivereira A, Frasson M. Benefit of against-the-rule astigmatism to uncorrected near acuity. $\mathcal{F}$ Cataract Refract Surg 1997;23:82-5.

28 Steiger A. Sehschärfe und astigmatismus. Arch Augenheilk 1902;44:15.

9 Eggers H. Estimation of uncorrected visual acuity in malingers. Arch Ophthalmol. 1945;33:23-7.

30 Friedman B. Acceptance of weak cylinders at paradoxic axes. Arch Ophthalmol 1940;23:720-6.

31 Tscherning M (translated by Weiland C). Physiologic optics. Philadelphia: Keystone, 1904

32 Javal E. Mémoires d'Ophthalmométrie. Paris: G Masson, 1890

33 Alpins NA. New method of targeting vectors to treat astigmatism. 7 Cataract Refract Surg 1997;23:65-75.
34 Lee JL, Belin MW. Comparison of subjectively refracted cylinder, topographic cylinder and topographically guided refractive cylinder in normal patients. Cornea 1996;15:220.

35 Binkhorst RD. The cause of excessive astigmatism with intraocular lens implants. Ophthalmology 1979;86:672-4.

36 Novis C. Astigmatism and the toric intraocular lens implant and other vertex distance effects. Surv Ophthalmol 1997;42:268-70.

37 Treutler B. Veber die krümmungsänderungen der hornhaut nach staroperationen. $Z$ Augenheilk 1990;3:484.

38 Jaffe NS Clayman HM. The pathophysiology of corneal astigmatism after cataract extraction. Trans Am Acad Ophthalmol Otolaryngol 1975;79:61530.

39 Axt JC. Longitudinal study of postoperative astigmatism. $\mathcal{F}$ Cataract Refract Surg 1987;13:381-8

40 Parker TP, Clorfeine GS. Long-term evolution of astigmatism following planned extracapsular cataract extraction. Arch Ophthalmol 1989;107:353-

41 Suzuki R, Tanaka K, Fujiwara N, et al. Remarkable postcataract against-therule astigmatism after phacoemulsification in 83 of 809 cases. Ann 年: $147-50$.

42 Richards SC, Brodstein RS, Richards WL, et al. Long-term course of surgically induced astigmatism. I Cataract Refract Surg 1988;14:270-6

43 Neumann AC, McCarty GR, Sanders DR, et al. Small incisions to control astigmatism during cataract surgery. F Cataract Refract Surg 1989;15:78-84.

44 Shepherd JR. Induced astigmatism in small incision cataract surgery. $\mathscr{f}$ Cataract Refract Surg 1989;15:85-8.

45 Hall GW, Campion M, Sorenson, et al. Reduction of corneal astigmatism at cataract surgery. F Cataract Refract Surg 1991;17:407-14.

46 Steinert RF, Brint SF, White SM, et al. Astigmatism after small incision cataract surgery. Ophthalmology 1991;98:417-24.

47 Cravy T. Routine use of a lateral approach to cataract extraction to achieve rapid and sustained stablisation of postoperative astigmatism. $\mathcal{F}$ Cataract Refract Surg 1991;17:415-23.

48 Long DA, Monica ML. A prospective evaluation of corneal curvature changes with 3.0 to $3.5 \mathrm{~mm}$ corneal tunnel phacoemulsification. Ophthalmology 1996;103:226-32.

49 Masket S, Tennen DG. Astigmatism stabilisation of $3.0 \mathrm{~mm}$ temporal clear corneal cataract incisions. F Cataract Refract Surg 1996;22:1451-5.

50 Roper-Hall MJ. Control of astigmatism after surgery and trauma. $\mathrm{Br} f \mathrm{Oph}-$ thalmol 1982;66:556-9.

51 Kronish JW, Forster RK. Control of corneal astigmatism following cataract extraction by selective suture cutting. Arch Ophthalmol 1987;105:1650-5.

52 Masket S. Comparison of suture materials for closure of the scleral pocket incision. $\mathcal{F}$ Cataract Refract Surg 1988;14:548-51.

53 Masket S. Keratorefractive aspects of the scleral pocket incision and closure method for cataract surgery. F Cataract Refract Surg 1989;15:70-7.

54 Cravy TV. Long-term corneal astigmatism related to selected elastic, monofilament, non-absorbable sutures. $\mathcal{F}$ Cataract Refract Surg 1989;15:61-9.

55 Drews RC. Astigmatism after cataract surgery: nylon versus mersilene. Ophthalmic Surg 1989;20:695-6.

56 Cravy TV. Calculation of the change in corneal astigmatism following cataract surgery. Ophthalmic Surg 1979;10:38-49.

57 Thornton SP. Astigmatic keratotomy: a review of basic concepts with cases reports. 7 Cataract Refract Surg 1990;16:430-5.

58 Rowsey JJ, Fouraker BD. Corneal coupling principles. Int Ophthalmol Clins 1996;36:29-38.

59 Lindstrom RL. The surgical correction of astigmatism: a clinician's perspective. Refract Corneal Surg 1990;6:441-54

60 Price FW, Grene RB, Marks RG, et al and the ARC-T Study Group. Astigmatism reduction clinical trial: a multicenter prospective evaluation of the predictablitiy of arcuate keratotomy. Arch Ophthalmol 1995;113:277-82.

$61 \mathrm{McD}$ onnell PJ, Moreira H, Clapham TN, et al. Photorefractive keratectomy for astigmatism. Arch Ophthalmol 1991;109:1370-3.

62 Snibson GR, Carson CA, Aldred GF, et al. One-year evaluation of excimer laser photorefractive keratectomy for myopia and myopic astigmatism. Arch Ophthalmol 1995;113:994-1000.

63 Stokes GG. Transactions of 19th meeting of the British Association for the Advancement of Science 1849, published London 1850

64 Rife CJ, Rapuano CJ. Residual error from correcting cylinders. $\mathcal{F}$ Cataract Refract Surg 1993;19:815.

65 Dunscombe KO. A new and remarkably sensitive test for astigmatism. $\mathrm{Br} F$ Physiol Optics 1933;7:112-28.

66 Linksz A. Determination of axis and amount of astigmatic error by rotation of trial cylinder. Arch Ophthalmol 1942;28:632-51.

67 Fearn WWL. The effect of axis errors on prescription comfort. Optician 1948;115:355-7.

68 Anderson DR. To tilt or not to tilt-a controversy rehashed. Surv Ophthalmol 1969;14:55-60.

69 Naylor EJ. Astigmatic difference in refractive errors. Br f Ophthalmol 1968; $52: 422-5$

70 Alpins NA. A new method of analysing vectors for changes in astigmatism. 7 Cataract Refract Surg 1993;19:524-33.

71 Schiller GM, Guthrie DS. Vector analysis. I Cataract Refract Surg 1993;20: 366-7.

72 Holladay JT, Cravy TV, Koch DD. Calculating the surgically induced refractive change following ocular surgery. $\mathcal{F}$ Cataract Refract Surg 1992;18: $429-43$.

73 Retzlaff J, Paden PY, Ferrell L. Vector analysis of astigmatism. $f$ Cataract Refract Surg 1993;19:393-8.

74 Lakshminarayanan V. Calculation of induced astigmatism due to cataract surgery using lens power matrices. Eur F Implant Ref Surg 1992;4:227-30.

75 Lakshminarayanan V, Srinivasan R, Smith P. Calculation of astigmatism induced due to cataract surgery. Eur f Implant Ref Surg 1992;4:232-3.

76 Toulemont PJ Serdarevic ON. Vectorial models of astigmatic variations. $f \mathrm{Fr}$ Opthalmol 1993;16:472-81.

77 Toulemont PJ. Multivariate analysis versus vector analysis to assess surgically induced astigmatism. $\mathcal{F}$ Cataract Refract Surg 1996;22:977-82.

78 Kaye SB, Campbell SH, Davey K, Patterson A. A method for assessing the accuracy of surgical technique in the correction of astigmatism. $\mathrm{Br} f \mathrm{Oph}$ thalmol 1992;76:738-40.

79 Olsen T. Simple method to calculate the surgically induced refractive change. F Cataract Refract Surg 1993;19:319.

80 Buzard K. New formula for vector change in astigmatism. $\mathcal{F}$ Cataract Refract Surg 1993;19:815-16. 
81 Rife CJ. More on calculating the surgically induced refractive change: two easy solutions. 7 Cataract Refract Surg 1993;19:320-2

82 Naeser K Vector analysis may not apply for astigmatic surgery. 7 Cataract Refract Surg 1993;19:668.

83 Naeser K, Behrens JK. Correlation between polar values and vector analysis. F Cataract Refract Surg 1997;23:76-81.

84 Olsen T, Dam-Johansen M. Evaluating surgically induced astigmatism. $\mathcal{F}$ Cataract Refract Surg 1994;20:517-22.

85 Naeser K, Behrens JK, Naeser EV. Quantitative assessment of corneal astigmatic surgery: expanding the polar values concept. F Cataract Refract Surg 1994;20:162-8.

86 Gartner WF. Astigmatism and optimetric vectors. Am f Optom 1965;42: 459-63.

87 Humphrey WE. Variable astigmatism lens and method for constructing lens. 1973 US Patent No 3,761,138.

88 Humphrey WE. Automated retinoscopy: the Humphrey vision analyser. The Optician 1977;173:17-27.

89 Naeser K. A new method to describe the surgically induced change in corneal astigmatism. Acta Ophthalmol 1990;68:33-6.

90 Naeser K. Conversion of keratometer readings to polar values. 7 Cataract Refract Surg 1990;16:741-5.

91 Naeser K. Assessment of surgically induced astigmatism; call for an international standard. 7 Cataract Refract Surg 1997;23:1278-80.

92 Thibos LN, Wheeler W, Horner DG. Power vectors: an application of Fourier analysis to the description ans statistical analysis of refractive error. Optom Vis Sci 1997;74:367-75.

93 Raasch TW. Clinical refraction in the three dimensional dioptric space revisited. Optom Vis Sci 1997;74:376-80.

94 Raasch TW. Quantitative model of corneal astigmatism from topographic data. Ophthal Vis Opt Tech Dig 1992;3:24-7.
95 Hjörtdal JO, Erdmann L, Bek T. Fourier analysis of video-keratographic data Ophthal Physiol Opt 1995:15:171-85.

96 Olsen T, Dam-Johansen M, Bek T, et al. Evaluating surgically induced astigmatism by Fourier analysis of corneal topography data. $\mathcal{F}$ Cataract Refract 96;22:318-23.

97 Freidman NE, Zadnik K, Mutti DO, et al. Quantifying corneal toricity from videokeratography with Fourier analysis. F Refract Surg 1996;12:108-13.

98 Keller PR, McGhee CNJ, Weed KH. Fourier analysis of corneal topographi data after photorefractive keratectomy. I Cataract Refract Surg 1998;24: $1447-55$.

99 Waring GO. Standardized data collection and reporting for refractive surgery. Refract Corneal Surg 1992;8(suppl):1-42.

100 Koch DD, Kohen T, Obstbaum SA, et al. Format for reporting refractive surgical data. 7 Cataract Refract Surg 1998;24:285-7.

101 Goggin M, Pesudovs K. Assessment of surgically induced astigmatism, toward an international standard. F Cataract Refract Surg 1998:24:1548-50.

102 Naeser K. Format for reporting surgically induced astigmatism on aggregate data. 7 Cataract Refract Surg 1998:24:1550-2.

103 Goggin M, Pesudovs K. Assessment of surgically induced astigmatism, toward an international standard II 7 Cataract Refract Surg 1998;24:1552-3.

104 Mathews JNS, Altman DG, Campbell MJ, et al. Analysis of serial measurements in medical research. BMF 1990;300:230-5.

105 Gross RH, Miller KM. Corneal astigmatism after phacoemulsification and lens implantation through unsutured scleral and corneal tunnel incisions. Am $\mathcal{f}$ Ophthalmol 1996;121:57-64.

106 Harris WF. Algebra of sphero-cylinders and refractive errors, and their means, variance and standard deviation. Am $f$ Optom Physiol Optics 1988;65:794-802.

107 Harris WF. Statistical inference on the mean dioptric power: hypothesis testing and confidence regions. Ophthal Physiol Opt 1990;10:363-72.

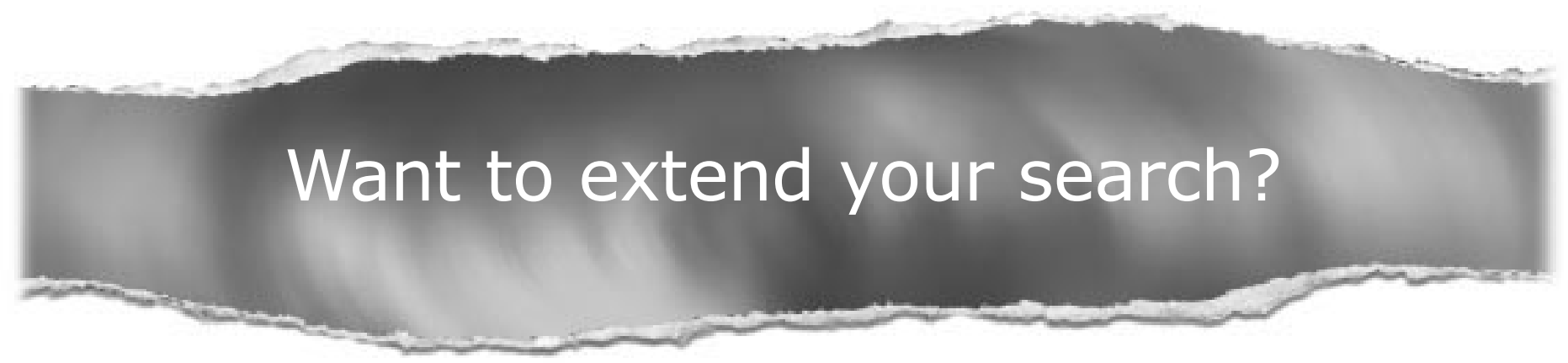

Cross journal searching

If you can't find what you are looking for in the British Journal of Ophthalmology you can extend your search across many of the more than 200 journals available for selection. You can restrict your search to specific subject areas (eg, clinical medicine, basic research), or select specific journals, or search all available titles.

www.bjophthalmol.com 